\title{
The effect of polymers onto the size of zinc layered hydroxide salt and its calcined product.
}

\begin{abstract}
Zinchydroxide nitrate, a brucite-like layered material was synthesized using $\mathrm{pH}$ control method. Poly(vinyl alcohol) and poly(ethylene glycol) were used at various percentages as size decreasing agents during the synthesis of zinchydroxide nitrate. SEM and PXRD showed the decrease of size and thickness of the resultant zinchydroxide nitrates. TG and surface area data confirmed the decrease of the particle sizes, too. When zinchydroxide nitrates were heat treated at $500{ }^{\circ} \mathrm{C}$, the physical properties of nano zinc oxides obtained depended on the parent material, zinchydroxide nitrate.
\end{abstract}

Keyword: Zinc layered hydroxide salt; Zinc oxide; PEG; PVA. 